\title{
La Biblioteca Central vista desde los ojos de un maquinista...
}

The central library seen from the driver's seat

\begin{abstract}
Gloria Adriana HeRnÁndez SÁnChez (1), Orlanda Angélica GaRRIDo YAÑes (2), Ramón TREJo GonZÁlez (3) y Rosa VALADÉz Olguín (4)
\end{abstract}

(1) Facultad de Ingeniería, Circuito Escolar s. n., Ciudad Universitaria, México D.F., C.P. 04510, adria568@hotmail.com. (2) Dirección General de Bibliotecas, orlanda@dgb.unam.mx. (3) Escuela Nacional de Trabajo Social, ram_trejo@yahoo.com.mx. (4) Facultad de Estudios Superiores Cuautitlán, rosycal_unam@hotmail.com

\section{Resumen}

Se describen detalladamente las líneas de acción seguidas a partir del año 2000 por la Biblioteca Central de la Universidad Nacional Autónoma de México para dar respuesta a la demanda creciente de los servicios que ofrece, así como los avances conseguidos. Se mejoraron los servicios tecnológicos y su aprovechamiento, las instalaciones de los usuarios y el personal, y se trató de fortalecer la imagen de la Biblioteca Central como un centro cultural. Para ello, se proyectó la habilitación de diversos espacios para dar cabida a exposiciones temporales relacionadas con la historia de la Biblioteca Central, el fomento de la cultura del libro y la lectura. Se ha instalado, además, en un lugar visible, un informativo electrónico que diera cuenta, día con día, de las efemérides de los autores sobresalientes representados en las colecciones de la Biblioteca.

Palabras clave: Bibliotecas universitarias. Servicios de consulta. Accesibilidad. Espacios culturales. Universidad Nacional Autónoma de México. Biblioteca Central. Méjico.

\section{Introducción}

Es a partir de esta nueva administración que inicia en el año 2000 que se comienza la actualización de los servicios de información de la Biblioteca Central, la cual se centró en la eliminación, en la mayor medida posible, de cualquier limitación de acceso tanto a los servicios como a las tecnologías de la información y la comunicación disponibles. Si queríamos que se aprovecharan al máximo cada uno de los recursos disponibles, incluidos los servicios electrónicos de información tanto los propios como los adquiridos por suscripción en la UNAM, a través de la Dirección General de Bibliotecas, debíamos brindar las condiciones de accesibilidad para que los usuarios hicieran un uso efectivo de ellos.

\begin{abstract}
The action lines followed by the Central Library of the Universidad Nacional Autónoma de México to face the increasing demand of their services are presented in detail from the year 2000 on, together with their results. An emphasis was put on improving the technological tools and the efficiency in their use. Reading and working spaces were extensively improved. Finally, steps were taken to position the library as a cultural centre: several spaces were rehabilitated for temporal exhibitions related to the history of the Central Library, the book culture and reading; and a electronic information point presenting the most outstanding authors in the library colections was developed.
\end{abstract}

Keywords: University libraries. Accesibility. Cultural events. Exhibitions. Universidad Nacional Autónoma de México. Central library. Mexico.

Asimismo, reconocimos que la actualización de los servicios no progresaría en impacto para nuestros usuarios sin una necesaria $e$ impostergable mejora de la imagen de nuestras instalaciones, que las transformaran en un foco de atracción para nuevos usuarios potenciales. Por ello iniciamos el proyecto de remodelación de los espacios físicos de la Biblioteca Central, el cual se llevó a cabo bajo tres directrices:

La primera, tenía que ver con la adaptación de las salas de lectura y consulta a la utilización de los nuevos servicios que el desarrollo tecnológico está ofreciendo, tales como el uso creciente de computadoras portátiles y el uso de redes inalámbricas.

La segunda, buscó rediseñar la distribución de las áreas de servicio para tener un mejor aprovechamiento del espacio de lectura, 
consulta y ubicación de las colecciones, así como crear un ambiente más cálido, de mayor operatividad y con una sustancial mejora de la iluminación, adecuada para el estudio individual.

La tercera era brindarle al personal académico y administrativo, adscrito a la Biblioteca, nuevas instalaciones en las que el confort y la mejor operatividad lograran tener un impacto sustancial en el desempeño de sus laborales cotidianas, así como incidir en la conformación de un equipo homogéneo de trabajo. La base de cualquier centro de trabajo es el personal que lo estructura, ya que sin su disposición, su ánimo, su dedicación e integración, ninguna institución lograría sus metas.

También se ha tratado de fortalecer la imagen de la Biblioteca Central como un centro cultural. Para ello, se proyectó la habilitación de diversos espacios para dar cabida a exposiciones temporales relacionadas con la historia de la Biblioteca Central, el fomento de la cultura del libro y la lectura. Se ha instalado, además, en un lugar visible, un informativo electrónico que diera cuenta, día con día, de las efemérides de los autores sobresalientes representados en las colecciones de la Biblioteca.

A través de poco más de ocho años transitados por la presente administración, no han sido pocos los caminos difíciles, las sorpresas y cuestas difíciles que hemos tenido que remontar desde que empacamos y subimos a este tren. El viaje, sin duda, ha sido intenso para llegar a la estación en que ahora nos encontramos, por lo que, como los buenos viajeros, ahora miraremos reflexivamente lo que ha quedado como experiencia de esta inmensa travesía a bordo de este tren: "Biblioteca Central".

\subsection{Departamento de Selección y Adquisición Bibliográfica}

El Departamento de Selección y Adquisición Bibliográfica es el encargado de seleccionar y adquirir colecciones bibliográficas y documentales equilibradas y representativas de los diversos campos del saber humano. Siempre con la misión de apoyar las tareas sustantivas de la universidad: docencia, investigación y difusión de la cultura.

Durante el periodo 2000 a 2007 se seleccionaron 121,194 títulos, con 178,194 volúmenes, se emitieron las respectivas órdenes de compra, sin embargo, sólo se adquirieron 81,745 títulos, con 121,108 volúmenes. Esto debido a que los proveedores no pudieron surtir los materiales solicitados. A finales del año 2004 se inició el análisis para fundamentar el desarrollo del Sis- tema Integral de Selección y Adquisición Bibliográfica (SISAB), promovido por el Departamento -con el apoyo de la Subdirección de Informática y de la Subdirección de Biblioteca Central- a fin de consolidar las herramientas informáticas que se aplican al cumplimiento de las funciones del Departamento.

\begin{tabular}{ccccc}
\hline & \multicolumn{2}{c}{ Selección } & \multicolumn{2}{c}{ Adquisición } \\
\hline Año & O.C. & Títulos & Volúmenes & Títulos \\
\hline 2000 & 427 & 16,652 & 18,091 & 10,591 \\
2001 & 434 & 14,217 & 20,092 & 10,859 \\
2002 & 419 & 15,797 & 22,878 & 10,209 \\
2003 & 617 & 16,561 & 26,000 & 10,295 \\
2004 & 569 & 13,235 & 20,129 & 7,817 \\
2005 & 549 & 15,048 & 23,852 & 11,304 \\
2006 & 667 & 14,216 & 24,612 & 10,300 \\
2007 & 634 & 15,306 & 22,540 & 10,370 \\
Total & 4316 & 121,032 & 178,194 & 81,745 \\
\hline
\end{tabular}

Tabla I. Material bibliográfico seleccionado $y$ adquirido

En el 2006 se desarrollaron, implementaron, evaluaron y liberaron los Módulos: Selección, Adquisición y Área Contable. Estos módulos nos han permitido optimizar el registro, el control y seguimiento de los diversos procesos a los que el libro es sometido desde su selección y adquisición, hasta el momento de su colocación en el estante.

En el 2003, el Departamento organizó “La Feria del Libro de la Biblioteca Central" y el objetivo de este evento fue dar a conocer las novedades editoriales disponibles en el mercado para que éstos sugirieran los títulos que debían incorporarse a las colecciones de la Biblioteca. Como resultado se tuvo una asistencia de más de 6,000 usuarios, que realizaron 4,400 sugerencias de compra. Posteriormente, se integró un programa cultural, el cual estuvo compuesto por: ponencias, presentaciones de libros, conferencias, talleres sobre los servicios y recursos de información de la DGB.

\begin{tabular}{lrrrrr}
\hline $\begin{array}{l}\text { Datos } \\
\text { generales }\end{array}$ & 2003 & 2004 & 2005 & 2006 & 2007 \\
\hline $\begin{array}{l}N^{\circ} . \text { de } \\
\text { expositores }\end{array}$ & 33 & 41 & 49 & 44 & 46 \\
$\begin{array}{l}\text { Asistentes } \\
\begin{array}{l}\text { Papeletas } \\
\text { entregadas }\end{array}\end{array}$ & 6,817 & 9,250 & 8,395 & 5,450 & 6,000 \\
$\begin{array}{l}\text { Papeletas } \\
\text { devueltas c/ }\end{array}$ & 2,389 & 1,801 & 2,717 & 2,402 & 1,294 \\
$\begin{array}{l}\text { títulos } \\
\text { Títulos selec. }\end{array}$ & 4,861 & 2,938 & 5,199 & 1,666 & 3.901 \\
\hline
\end{tabular}

Tabla II. Datos representativos de la Feria del Libro 
En agosto del 2006 se inició el "Programa Descarte", el cual tiene como objetivos identificar las fortalezas y debilidades de las colecciones, a fin de corregirlas para cubrir las necesidades de los usuarios, así como planear sistemáticamente su desarrollo.

También se seleccionaron y adquirieron materiales bibliográficos que complementaran sustancialmente las colecciones especiales de la Biblioteca. Entre los títulos adquiridos en el 2007 destacan:

- Una edición facsimilar del Cantar del Mío Cid editado en 1207, de la cual se adquirió el número 869 de los 999 ejemplares que se imprimieron.

- El Quijote, en edición de 1892 hecha en México por la Imprenta de Ignacio Cumplido.

- La Tauromaquia de Francisco de Goya, (se adquirió el ejemplar 666 de 998 que se imprimieron) y dos libros de Torear y la Tauromaquia, con reproducción de sus famosos grabados.

- Una carpeta de láminas facsimilares de Salvador Dalí, que ilustró la obra de Michel de Montaigne (se conservan 15 de las 16 que realizara). Se reproducen a tamaño real, en papel de algodón Fedrijoni Tintoretto, similar al que sirvió de base.

- Memoria instructiva sobre el maguey o agave mexicano: Contendrá los nombres con que se conocen 33 variedades en los llanos de Apan (Obra rara y curiosa sobre un icono de México: el maguey, 1937).

- Himno Nacional (manuscrito): compuesto y dedicado al Exmo. Sr. General de División benemérito del la patria Don Antonio López de Santa Ana (1 $1^{\text {a }}$. Edición del himno nacional, Autor Ynnocenzo Pellegrini, 1853).

Por otra parte, se implementó el programa Alerta bibliográfica, el cual tuvo como objetivo difundir, entre la comunidad universitaria, las novedades bibliográficas recibidas cada mes.

En el año 2001 se reubicó el Departamento de Selección y Adquisición Bibliográfica del $9^{\circ}$ piso al basamento. El motivo principal para este desplazamiento fue el peso excesivo de los materiales bibliográficos ubicados en el departamento, así como el continuo movimiento de personas y libros que origina las funciones normales del Departamento. Se reciben diariamente un total de 20 a 30 proveedores.

Este departamento continuará seleccionando y adquiriendo materiales documentales, incrementando y actualizando constantemente los acervos bibliográficos de la Biblioteca Central, atendiendo las funciones sustantivas de la universidad que son: investigación, docencia y extensión de la cultura.

\subsection{Circulación Bibliográfica y Turno Especial}

El Departamento de Circulación Bibliográfica de la Subdirección de Biblioteca Central es el que controla el acervo bibliográfico general distribuido en once salas de lectura y un mostrador en el cual los usuarios pueden realizar sus trámites de expedición y actualización de credenciales, constancias de no adeudo de libros, préstamo a domicilio, así como catálogo en línea para localizar las obras bibliográficas a través de treinta computadoras conectadas en red, distribuidas en el edificio.

El turno especial opera los sábados, domingos y días festivos, representa la continuación de los servicios bibliotecarios como respuesta a la necesidad de la comunidad universitaria de contar, en fines de semana y días de asueto, con los beneficios que la Biblioteca Central brinda en su horario regular. Por tal motivo, la Dirección General de Bibliotecas decidió abrir sus puertas en jornadas adicionales de trabajo.

Su objetivo principal es poner a disposición del usuario, en el menor tiempo posible, el material bibliográfico que requiere para sus estudios o investigación, mediante el apoyo del personal bibliotecario, a través de 11 secciones con sus respectivas colecciones y salas de lectura.

Este departamento atiende los servicios bibliotecarios: préstamo de libro a domicilio, la devolución, el préstamo de libros en las salas, la expedición y actualización de credenciales, y las visitas guiadas.

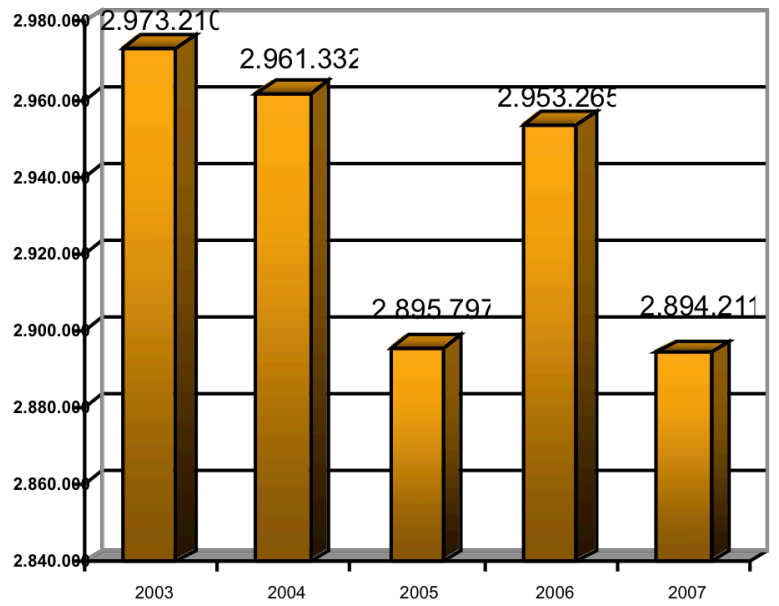

Gráfico 1. Asistencia de usuarios a la Biblioteca Central, $2003-2007$ 
Durante el 2000 al 2007 se prestaron 7'395,917. Se atendieron aproximadamente 20'177,453 usuarios, se expidieron 13'649,920 credenciales, se actualizaron 121,853 y se atendieron 295 visitas y se registró una asistencia de 20 '810,193 usuarios.

Este espacio se ha transformado para brindar servicios adecuados a este dinámico entorno. Por ello se trazaron cuatro líneas de acción para alcanzar tal fin, la primera encaminada al fortalecimiento y actualización de los servicios bibliotecarios. El incremento en la afluencia de usuarios en la Biblioteca Central y la mejoría en la calidad de los servicios bibliotecarios, permitieron alcanzar las metas programadas para dicho período.

Por lo anterior, en el año 2002 se amplió el horario de servicio. En este momento la Biblioteca Central es la única de todas las bibliotecas que forman parte del sistema UNAM que ofrece un horario de 11 horas ininterrumpidas de servicios, de $8: 30$ a $21: 30$ hrs., de lunes a domingo, y días festivos.

La segunda acción tuvo que ver con el acondicionamiento de espacios físicos en Biblioteca Central. Los primeros cambios que se realizaron en este Departamento fueron el mostrador de préstamo de la Planta Principal y las oficinas de la Subdirección. También se reorganizó la estantería, se abrió la puerta norte y se rehabilito la fuente del lado norte. De igual forma, se dignificaron los baños de la planta principal; y en los accesos se quitaron los torniquetes para sustituirlos por contadores electrónicos, y en las salidas colocamos los controles de verificación de préstamo a domicilio.

Durante el 2003 se inició la Campaña Financiera Pro Remodelación y Equipamiento de la Biblioteca Central, con el respaldo de Fundación UNAM, siendo uno de sus primeros resultados el programa Amigos de la Biblioteca Central. Todos los fondos económicos recaudados durante esta campaña fueron canalizados a los proyectos de remodelación y equipamiento de la Biblioteca Central.

En el año 2005 se inició la remodelación del primer piso, durante este año día con día se revisaron los cambios físicos del espacio, siempre con el propósito de tener la sala de lectura óptima de acuerdo a las condiciones físicas de su construcción.

Es muy interesante observar que la Biblioteca Central a 50 años de su construcción ha tenido que superar algunas adaptaciones y remodelaciones para estar a la vanguardia del conoci- miento y figurar continuamente como centro de información, social y cultural. Por tal motivo la riqueza de estas remodelaciones están plasmadas en los nuevos servicios que se brindan en la Biblioteca Central, como son el Jardín Cibernético, la sala de discapacitados y la remodelación minimalista en las salas de lectura.

La tercera acción que se llevó a cabo estuvo encaminada a la automatización de los servicios, a finales del 2005. Los 24 equipos de cómputo conectados al catálogo de la Biblioteca se cambiaron por equipos de pantalla plana y mayor capacidad de memoria. Los equipos asignados para el préstamo a domicilio también se actualizaron. Esta acción fortaleció sustancialmente las actividades del departamento.

De igual manera, se llevó a cabo la actualización del sistema integral ALEPH 500 versión 16.02. El cambio de versión ayudó a consolidar las estadísticas de los préstamos, también sirvió para innovar servicios como el autopréstamo y el resello por Internet. Además, brindó la posibilidad de contar con una interfaz más amigable y sencilla para el usuario.

En cada uno de los periodos vacacionales de estos siete años se realizaron las tareas de inventarío de la colección, mantenimiento, limpieza profunda y ordenamiento de la colección en las estanterías abiertas. Todo esto con el objeto de mantener en óptimas condiciones el espacio físico y las colecciones.

En dos ocasiones se llevó a cabo el inventario de aproximadamente 400,000 volúmenes, tarea sustantiva del departamento de Circulación Bibliográfica y Turno Especial. Además, para realizar tan ardua labor fue necesario el apoyo de todos los departamentos que conforman la Biblioteca Central y la Subdirección de Informática. En el primer inventario se codificaron los libros para su identificación en el sistema de préstamo. El segundo inventario, efectuado en el verano del 2007 , se realizó de manera ágil y oportuna debido a que el material ya contaba con esta codificación, por lo que fue más sencillo cotejar los datos del libro a través de las recolectoras.

Este levantamiento del inventario (agosto 2001, julio 2007) permitió obtener una relación completa, ordenada y contrastada físicamente del acervo de la biblioteca, además del listado de los materiales documentales perdidos, una relación de materiales documentales enviados a los encuadernadores, al fondo antiguo, a área de restauración y al sótano donde se encuentran los libros mutilados y deshidratados. También permitió identificar los títulos que tenían número 
de adquisición duplicado y los que no estaban cargados en la base de datos.

La encuadernación permanente de la colección permitió mantener en óptimas condiciones físicas la colección bibliográfica general, además de ponerla a disposición de los usuarios.

Actualmente el Departamento necesita consolidar los proyectos de automatización de los servicios bibliotecarios y desarrollar estrategias para aplicar tecnologías de la información a los servicios para poner a disposición de los usuarios la modalidad de autopréstamo de libros, registro automático de usuarios, devolución automática de libros y resello del préstamo de libros vía Internet.

Asimismo, necesita implementar mecanismos para que la Biblioteca Central siga siendo un verdadero depósito de conocimiento que difunda continuamente información en diversos formatos, incluyendo los electrónicos, sin dejar de lado la importancia del libro impreso.

\subsection{Departamento de Consulta}

Corresponde al Departamento de Consulta la función de proporcionar a la comunidad universitaria servicios de orientación, búsqueda y recuperación de información tanto en formatos impresos como electrónicos, además de brindar información e instrucción sobre el uso y aprovechamiento de los recursos informativos de la biblioteca y los del Sistema Bibliotecario de la Universidad (SBU).

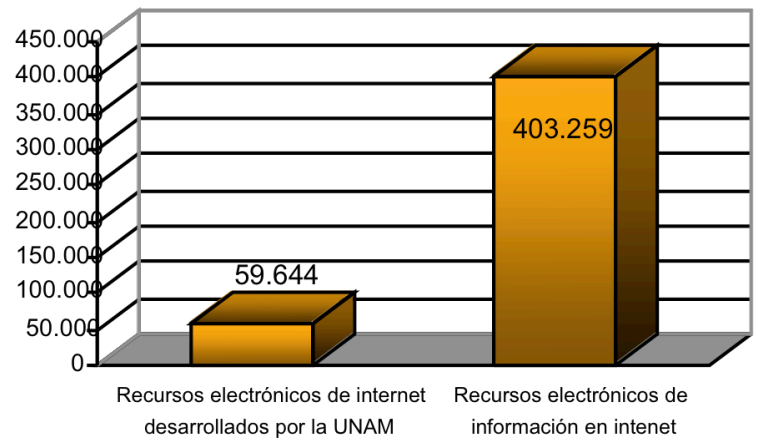

Gráfico 2. Servicios proporcionados por el Departamento de Consulta (2000-2007)

Para cumplir esta función, cuenta con una colección de obras de consulta (diccionarios, enciclopedias, manuales, atlas, anuarios, entre otros) de carácter multidisciplinario con más de 16,000 volúmenes; además de una importante colección de recursos electrónicos de información, unos desarrollados por la propia Universi- dad, y otros adquiridos por suscripción con la finalidad de apoyar los planes y programas de estudios que se imparten la UNAM. En total se cuenta con: 161 bases de datos referenciales y de texto completo nacionales e internacionales, 19,302 títulos de revistas electrónicas, más de 7,945 libros electrónicos, 46,966 tesis digitales, así como catálogos electrónicos y 20 bases de datos desarrolladas en la Universidad, todas éstas integradas para su consulta en la Biblioteca Digital.

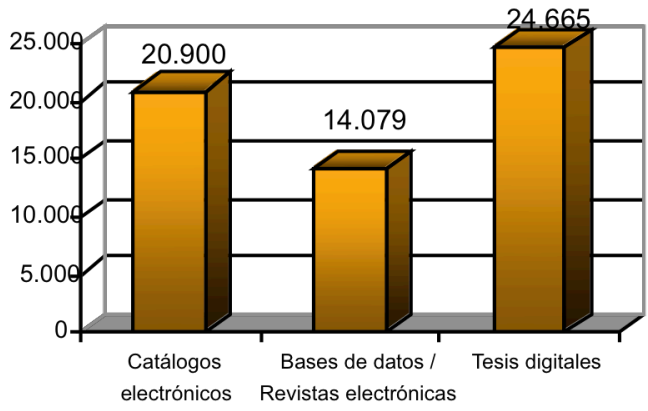

Grafico 3. Tipo de recursos utilizados

Las colecciones antes mencionadas se completan con una variedad de servicios de información que la Biblioteca Central pone a disposición de la comunidad universitaria; entre éstos se encuentran:

- Orientación e información: Proporciona orientación sobre los horarios, servicios y recursos con los que cuenta la biblioteca y el SBU.

- Búsqueda y recuperación de información: Permite y facilita la búsqueda y recuperación de información sobre algún tema que el usuario requiera en los recursos documentales impresos y electrónicos con que se cuenta.

- Acceso a Internet y paquetería Office: Se brinda a los usuarios la posibilidad de acceder a estos servicios, a través de una sala de cómputo equipada con 45 computadoras de última generación diseñada a propósito para este servicio.

- Obtención de documentos: Este servicio consiste en la búsqueda, recuperación y entrega de documentos que han sido solicitados por el usuario para satisfacer una necesidad de información.

- Préstamo interbibliotecario: Solicita material documental (libros) a las bibliotecas con las cuales se tiene establecido un convenio de colaboración para dicho fin. 
- Pregúntale al referencista: Permite al usuario contactar, en cualquier parte del mundo, a un referencista de la Biblioteca para exponerle alguna duda. El usuario envía su pregunta por chat o formulario electrónico, y el referencista responde en forma referencial (fuentes que pueden consultar) a su necesidad de información.

- Formación de usuarios: Se han diseñado talleres y sesiones informativas para que los usuarios de la Biblioteca puedan conocer y desarrollar habilidades en el uso y aprovechamiento de los recursos de información con que cuenta la Universidad.

En el año 2000 se presentó el documento: Diagnóstico y Proyecto del Departamento de Consulta. En éste se mostró la situación en la que se encontraba el Departamento (colección, servicios, recursos humanos y materiales, con especial atención en el equipo de cómputo); así como un plan de acciones encaminadas a mejorar, fortalecer y desarrollar nuevos servicios para la comunidad universitaria.

Con la adquisición de los primeros recursos electrónicos de información ( 66 bases de datos y 500 títulos de revistas) y el uso creciente de Internet, la administración tomó la decisión de equipar al Departamento con equipo de cómputo que garantizara el acceso a estos nuevos servicios, tanto en forma referencial como en texto completo. Estos cambios repercutieron en un notable incremento de servicios $(7,125$ usuarios, de los cuales 721 utilizaron las bases de datos en línea.)

Como parte del Proyecto del Departamento de Consulta, el 7 de marzo de 2001, se inauguró la Videoteca. En su primer año de servicio brindó atención a 2,492 usuarios y prestó 4,323 videos. Además se desarrolló el catálogo de materiales audiovisuales de la Biblioteca Central. Actualmente la videoteca tiene una colección de más de 4,100 títulos que cubren las principales áreas del conocimiento. El material puede ser consultado hasta por diez usuarios en forma simultánea.

Ante el crecimiento de la demanda se decidió ampliar los servicios del Departamento, que se ofrecían sólo de lunes a viernes, a fines de semana y días festivos. Esta decisión se tomó para todos los servicios de la Biblioteca Central a partir del $1^{\circ}$ de abril del 2002. Bajo este horario se atendió en total a 43,313 usuarios, durante el 2002.

Con un nuevo repunte del uso de los servicios fue necesario realizar, en el 2003, la remodelación del Departamento, en la que se cambio el mobiliario y la ubicación de la estantería; asimismo, se dio una nueva distribución a la colección y se amplió la Sala de Consulta de los Recursos Electrónicos de Información. Con esta remodelación se privilegió la vista de la zona poniente del campus y se permitió una vista panorámica del campus, sobre todo del edificio de Rectoría.

En este mismo año se empezó a proporcionar el servicio de consulta a tesis digitales con una colección de 40,000 tesis de 1998 a 2001. Se atendió a 1,288, en la primera fase del servicio. Esto se traduce en un incremento de 46,932 usuarios que hicieron uso de la sala de recursos electrónicos de información.

En el año 2004 se puso en marcha la automatización del préstamo interbibliotecario, con el fin de tener el control de los préstamos que se realizan en la Biblioteca (préstamo a domicilio e interbibliotecario). Esta automatización incluyó la digitalización de las firmas del personal autorizado para este servicio y la asignación de un número de usuario a cada institución.

En este mismo año se identificó un problema en los usuarios de la Biblioteca: muchos desconocían los servicios, recursos y el uso de los catálogos con los que cuenta la biblioteca (libros, revistas, materiales audiovisuales y tesis). Por esta razón, se lanzó el Programa de Habilidades para el Uso de los Recursos de Información. Este programa tiene como objetivos: a) dar a conocer los servicios y recursos electrónicos de información que la Universidad ha adquirido para la comunidad universitaria; y b) desarrollar en los usuarios las habilidades informativas para que localicen la información que requieran para sus tareas de estudio, docencia e investigación.

En agosto del mismo año se realizaron sesiones informativas para los alumnos de primer ingreso a la licenciatura sobre los recursos y servicios que ofrece la biblioteca, con una duración de 30 minutos. En este primer año se atendió a 5,112 alumnos de primer ingreso a la licenciatura. Como parte del Programa se diseñó un taller dividido en tres módulos:

- Módulo I: Cómo utilizar los catálogos electrónicos de la Biblioteca Central. Tiene una duración de 2 horas y está dirigido a los alumnos de nivel de licenciatura y posgrado inscritos en la UNAM.

- Módulo II: Los recursos electrónicos de información. Tiene una duración de 4 horas y está dirigido a los alumnos de nivel de licenciatura y posgrado inscritos en la UNAM.

- Módulo III: Temático o a la carta. Es un taller a petición de grupos de alumnos o de un pro- 
fesor para sus alumnos sobre un tema de interés.

En total asistieron 380 alumnos, quienes conocieron y desarrollaron las habilidades adecuadas para el uso de los recursos electrónicos de información con que cuenta la Universidad.

En el 2005, el departamento inauguró el primer servicio de consulta en línea en la UNAM, llamado Pregúntale al referencista.

En el 2006, se automatizó el Servicio de Obtención de Documentos (SOD) con la aplicación Celsius (desarrollada por la Universidad Nacional de la Plata). A través de este sistema, un usuario registrado puede solicitar todo tipo de material bibliográfico, desde artículos de revistas, capítulos de libros, tesis, hasta conferencias de congresos y patentes. Además, todo el proceso es lineal tanto para el usuario (sitio Web personal) como para el administrador (sitio Web del SOD). La Biblioteca tiene dos categorías de usuarios para este servicio: usuarios registrados (en su mayoría son instituciones de educación superior ubicadas en el interior del país) que han realizado un depósito (monto mínimo $\$ 1,000.00 \mathrm{M}$. N.) y usuarios no registrados, es decir, que solicitan ocasionalmente el servicio. Los usuarios deben conocer previamente las condiciones y políticas del servicio expuestas en el sitio Web de la biblioteca (http://bc.unam.mx) en la sección de Servicios, opción Obtención de Documentos. Es importante mencionar que este software ha sido adoptado por el Ibero-America Science and Technology Education Consortium (ISTEC), del cual la UNAM forma parte, y por otras bibliotecas académicas de Latinoamérica. Celsius es gratuito para la UNAM como miembro de ISTEC.

En el último año (2007) se dio énfasis en las mejoras de los catálogos de la Biblioteca Central. Respecto a la colección de consulta. Se realizó el inventario de la colección con 16,000 volúmenes y se identificó, en el catálogo, la ubicación física de la colección con la leyenda Planta Principal, Lado Poniente, así como el nombre de la colección a la cual pertenece Colección de Consulta. Con estas leyendas, el sistema reconoce los títulos que no pueden salir de la Biblioteca

Es necesario que los servicios de información que proporciona el Departamento de Consulta se fortalezcan a la par del surgimiento de nuevas tecnologías de información; además, que la colección esté en constante actualización para que pueda cumplir con el objetivo de apoyar a los planes y programas de estudios de nuestra Universidad.

\subsection{Departamento de Tesis}

Por reglamento, es el encargado de recibir, conservar, almacenar y difundir las tesis que realizan los egresados de nivel licenciatura y posgrado, tanto de la UNAM como de las escuelas incorporadas. En promedio, anualmente se reciben 12,000 tesis.

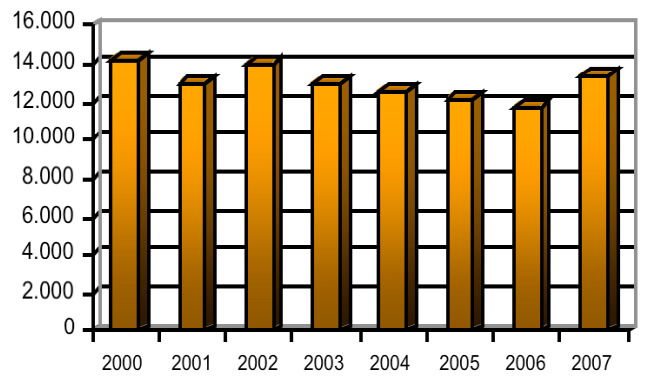

Gráfico 4. Recepción de tesis por los usuarios que obtuvieron algún grado académico

\subsubsection{Servicios}

El préstamo de las tesis, en sus diferentes formatos, es por estantería cerrada. Una vez que el usuario cuenta con los datos de los materiales que requiere para su consulta, procede a llenar la papeleta de préstamo y solicita al bibliotecario la entrega de los materiales. Si el usuario lo desea, puede pedir también el fotocopiado de alguna parte de los mismos.

A partir del $1^{\circ}$ de abril de 2002, con base en el proyecto de ampliación de horario y extensión de los servicios, el Departamento homologó su horario al de la Biblioteca Central. Desde entonces ofrece todos sus servicios de 8:30 a 21:30 horas de lunes a domingo, incluyendo días festivos, con excepción de los periodos vacacionales de verano e invierno.

El departamento cuenta con una sala de consulta equipada con nueve equipos de cómputo de última generación para la consulta del catálogo de tesis.

\subsubsection{Colección impresa}

La colección de tesis impresas está conformada aproximadamente por 25,000 títulos pertenecientes a los años 2004 y 2005 . Se encuentra ubicada en el $8^{\circ}$ piso, en la sala oriente. Dentro de esta colección se distinguen cuatro secciones: Licenciaturas de la UNAM, Posgrados de la UNAM, Especialidades y Licenciaturas de escuelas y universidades incorporadas a la UNAM. Cada uno de los trabajos se encuentra ordenado por la clave de la carrera, año y autor. 


\subsubsection{Colección microfilmada}

La colección de tesis microfilmadas incluye desde 1914 hasta 1998, así como los años 2002 y 2003. Con base en el año de la tesis, podemos distinguir dos tipos de formato dentro del microfilm: los títulos de 1914 a 1979 se encuentran en cartucho, y los de 1980 a 2003 se encuentran en rollo.

Los cartuchos o rollos son películas de $16 \mathrm{~mm}$. por 100 pies de largo, con reducción de 24 a 27x (de acuerdo al texto). Tienen una capacidad mínima de almacenaje de 3,000 imágenes con orientación de modo cómic. Existen a la fecha aproximadamente 281,800 títulos de tesis en estos formatos.

Se cuenta, además con rollos originales en películas (plata), los cuales son guardados en un almacén en el basamento de la Biblioteca Central para su preservación y resguardo. Los rollos copia o duplicados se encuentran en película denominada diazo. Con este formato se proporciona el servicio de consulta. La estructura e información contenida en cada rollo es la siguiente: 100 imágenes de guía al inicio y final de cada rollo; clave y número de rollo; certificación de la empresa que realizó la microfilmación; logotipo de la institución, en este caso el de la UNAM; descripción de facultad y/o escuela, grado de la tesis, carrera y clave de la misma, fecha de impresión (todo en una sola imagen); índice descriptivo de cada rollo conteniendo como encabezado los datos inmediatamente anteriores, y el índice de las tesis a través de una numeración progresiva con la que inicia y termina el rollo con base en su orden alfabético, autor(es) de la(s) tesis, y título; y las imágenes propiamente dichas de la tesis (texto) ordenadas con base en el índice.

\subsubsection{Colección Digital}

La colección de tesis digitales surge a partir del proyecto: Tesis Digitales, cuya intensión era formar la colección de tesis, en formato digital, más grande y actualizada del país y América Latina. La realización de dicha colección se llevó a cabo en 2 fases.

La primera, en el año 2001, abarcó la digitalización de las tesis de 1998 al 2001. En total, sumaron 42,150 tesis digitalizadas. Posteriormente, la Subdirección de Informática se encargó de hacer las ligas y el tratamiento de la información con el registro en la base de datos TESIUNAM.

La segunda fase consistió en la creación de un sistema o software en ambiente Windows o en HTML, que permitiera al propio usuario capturar su información: referencia bibliográfica de la tesis y el texto completo de la misma. Con este procedimiento, el alumno se presenta en el Departamento para que se le valide su información y se haga la creación del registro en TESIUNAM. En 2003, la Subdirección de Informática subió esta información al catálogo en línea para proporcionar acceso electrónico a las tesis.

El Departamento de Tesis, por su parte, se encarga de llevar a cabo la transferencia a la Secretaría Técnica de Biblioteca Digital para el proceso de incorporación a la base de datos TESIUNAM.

La digitalización de las tesis de la primera fase del proyecto finalizó en el año 2003 y puede ser consultada a través del catálogo TESIUNAM en formato de texto completo. Actualmente, el Catálogo de TESIUNAM cuenta con 371,547 registros, de los cuales 68,860 cuentan con liga a texto completo.

Respecto a la segunda etapa, iniciada en el 2003, se creó el Sistema para la Recepción, Administración y Recuperación de Tesis Electrónicas (SIRARTE). Sin embargo, no es hasta el 2006 cuando se le solicita a la Subdirección de Informática su actualización, con la finalidad de hacerlo más accesible a los tesistas. Actualmente, se han llevado a cabo reuniones con la Subdirección de Informática y el Departamento de Tesis para lograr dicho fin.

Para cubrir las necesidades de ingreso de las tesis en formato electrónico a TESIUNAM, se crea, en el primer trimestre del 2006, el Sistema de Tesis Digitales (SITEDIG) versión 1.0 2006, dentro del Departamento de Tesis. El sistema está conformado por los módulos: "Crear índice temático" y "Crear registro de datos". Entre sus características más representativas se encuentran: la revisión de tesis digital (archivos PDF); la generación de tablas de contenidos referenciales de tesis electrónicas; la catalogación y almacenamiento de registros de tesis digitales de acuerdo con el formato MARC y compatible con ALEPH 500; el ajuste de Cutter de autor en cada registro de tesis; y la generación del archivo de encriptación para cada tesis por parte de Biblioteca Digital.

\subsubsection{Migración}

En el 2006 se realiza la migración de las bases de tesis TESIUNAM y TESIS@UNAM del Sistema Aleph, versión 300 a la versión Aleph 500 . Ésta migración permitió corregir y depurar gran parte de los registros del catálogo de TESIUNAM, además permitió catalogar los registros en formato MARC $21 \mathrm{y}$, conjuntar, en una sola base, todos los registros de las tesis de la Biblioteca Central en sus diferentes formatos: 
impresas, microfilmadas y texto completo. Con esto se logró una reducción considerable de los tiempos de búsqueda de los usuarios.

\subsubsection{Remodelación del Departamento}

A mediados del año 2000 se inicia la remodelación y reestructuración del Departamento: Del lado oriente quedó la colección de tesis impresas de 1998 a la fecha y el Área de Recepción de Tesis. Del lado poniente se ubicó la jefatura del Departamento, el área de Catalogación y Mantenimiento de TESIUNAM, la colección de tesis en microfilm, el mostrador de préstamo para dicha colección, y, a partir del 2000 , la sala de lectura y consulta de tesis en formato impreso y microfilm.

\subsubsection{Actualización de equipos y red local}

Con la finalidad de ingresar las tesis en formato digital a TESIUNAM, en el 2006, se cambiaron los equipos de cómputo del personal (14) y los equipos para la consulta del catálogo (9), así como dos equipos para la recepción de tesis en formato digital. También se cambió la red interna del Departamento, con lo cual se logró mejorar los tiempos de respuesta de los equipos para la consulta del catálogo de TESIUNAM y para el ingreso de nuevos registros a través del Sistema de Tesis Digitales. En septiembre de 2007 se liberó la bitácora en formato electrónico para la recepción de tesis y sello de no adeudo de material para optar a un grado académico dentro de la UNAM.

\subsubsection{Logros y prospectiva}

En el transcurso de estos ocho años el Departamento de Tesis ha logrado avances considerables en cuanto a la conservación y preservación de las tesis gracias a que la microfilmación de las mismas se ha llevado a cabo de manera continua, lo cual nos ha permitido tener microfilmado hasta el año 2003.

Asimismo, la incorporación de nuevas tecnologías dentro del Departamento permitió la continuidad del proyecto de digitalización de las tesis. Sin embargo, aún se requiere dar mayor difusión a este proyecto a fin de involucrar a todas las escuelas y facultades de la UNAM para que el tesista pueda hacer el registro de su tesis desde la Biblioteca de su facultad o escuela. Con esto se agilizaría el trámite global para la titulación.

Finalmente, es impostergable la adaptación, en el $8^{\circ}$ piso, del área para la consulta de tesis en formato digital. Actualmente, este servicio está disponible en el Departamento de consulta, lo cual ocasiona el continuo congestionamiento de áreas que no tienen que ver con dicha función.

\subsection{Departamento de Publicaciones Periódicas}

El objetivo del Departamento depende de la buena organización y disponibilidad del acervo de publicaciones periódicas primarias en las áreas científicas, técnicas, humanísticas y de divulgación con que cuenta la Biblioteca Central.

\subsubsection{Colección}

Hasta el 2007, la Biblioteca cuenta con 3,120 títulos de revistas, científicas, técnicas, humanísticas y de divulgación, y la suscripción a diversos diarios de circulación nacional. De acuerdo con un inventario de publicaciones seriadas antiguas se cuenta con un total de 371 títulos (172 mexicanos y 199 extranjeros), correspondientes a 15,441 fascículos.

\subsubsection{Servicios a los Usuarios}

Se proporciona préstamo únicamente en sala, así como servicio de orientación, consulta a bases de datos, consultas a directorios telefónicos, archivo vertical, visitas guiadas, y fotocopiado.

\subsubsection{Títulos más consultados}

En 2007 se consultaron 103,010 fascículos. De éstos los más consultados fueron revistas de divulgación (38.31\%), seguidas por las de humanidades $(36.13 \%)$, científicas $(16.98 \%)$ y técnicas $(8.58 \%$.) Entre los títulos más consultados se encuentran la colección del Instituto Nacional de Geografía y Estadística (INEGI) con 2,800 volúmenes y la colección OCDE (Organización para la Cooperación y el Desarrollo Económico) con 2,302 volúmenes. La Biblioteca Central, a través del Departamento, es la depositaria de estas colecciones.

Periódicamente, se reciben materiales estadísticos: censos de población nacionales y de los estados, censos económicos, censos agropecuarios, anuarios estadísticos -nacionales, estatales y delegacionales-, e índices de producción, entre otros.

La colección de Publicaciones oficiales consta de mil volúmenes de publicaciones gubernamentales provenientes de las diferentes Secretarías, Organismos Federales y de los Estados de la República.

La colección de Publicaciones UNAM consta de 400 títulos y 800 fascículos, pertenecientes a las distintas escuelas, centros, institutos y dependencias que la conforman. 
La colección del Archivo Vertical posee alrededor de 8,000 documentos; El Diario Oficial de la Federación; 12 diarios de circulación nacional e internacional, entre los que destacan: Diario Monitor, El Financiero, El Universal, Excélsior, La Jornada y Reforma. Los diarios se conservan únicamente durante un año debido a la falta de espacio en el Departamento.

La colección de Material Bibliohemerográfico del Fondo Antiguo (siglo XIX y XX) posee aproximadamente 1,750 títulos. La biblioteca también custodia el $67 \%$ de los volúmenes del Índice de Revistas Mexicanas de Investigación y Tecnología, cifra que difícilmente podría tener una biblioteca, dado su carácter multidisciplinario.

Los 10 títulos de revistas más solicitados en el periodo 2001-2006 se presentan en la tabla III.

\begin{tabular}{|c|c|c|c|}
\hline$N^{\circ}$ & Título & $N^{\circ}$ & Área \\
\hline 1 & INEGI (Colección) & 5,725 & Humanística \\
\hline 2 & Proceso & 3,600 & Humanística \\
\hline 3 & Investigación y ciencia & 2,986 & Divulgación \\
\hline 4 & $\begin{array}{l}\text { Revista de psicología } \\
\text { general y aplicada }\end{array}$ & 1,705 & Humanística \\
\hline 5 & Infancia y aprendizaje & 1,230 & Humanística \\
\hline 6 & Mundo científico & 1,084 & Divulgación \\
\hline 7 & Salud mental & 919 & Científica \\
\hline 8 & Gaceta UNAM & 909 & Divulgación \\
\hline 9 & Psiquis & 900 & Humanística \\
\hline 10 & $\begin{array}{l}\text { Revista Intercontinental de } \\
\text { psicología y educación }\end{array}$ & 503 & Humanística \\
\hline
\end{tabular}

Tabla III. Publicaciones periódicas más utilizadas.

\subsubsection{Diarios o Periódicos}

Los diarios tuvieron 6,612 , consultas, distribuidas de la siguiente manera: El Universal, con 1,384 consultas; La Jornada, con 1,285; Reforma, con 1,059; Milenio con 814; El Financiero, con 507; El Excélsior con 353; El País, con 262, El Economista, con131; Crónica, con 115, Diario Monitor con 73; y el Uno más Uno, con 67 consultas. El Diario Oficial de la Federación, por su parte, tuvo 562 consultas.

También se maneja el número de ejemplares solicitados en cada consulta. Para el 2007, el dato referente fue de 30,344 ejemplares, distribuidos de la siguiente forma: en primer lugar el Diario Oficial de la Federación con 5, 942 ejemplares. La Jornada con 5, 382, El Universal con 4, 541, Reforma con 3, 695, Milenio con 3, 619, Crónica con 250, Uno más Uno con 204 y por último, Diario Monitor con 195 ejemplares.

\subsubsection{Recepción de fascículos desde 2000}

En el 2001, ingresaron al Departamento 8,886 fascículos por suscripción y donación; en 2002, 14,447 fascículos; en 2003, 9,472 fascículos; en $2004,7,840$ fascículos; en 2005, 8,513 fascículos; finalmente, en 2006, 6,725 fascículos.

\subsubsection{Apoyos técnicos y remodelación}

Los periódicos son adquiridos desde 2006 por suscripción, con el consecuente beneficio al contar con suplementos especiales, así como acceso a la versión digital de algunos diarios. Esta última opción, en ciertos periódicos, ventaja de realizar búsquedas retrospectivas.

En el año 2000 las colecciones de revistas fueron reubicadas en el séptimo piso, donde se adaptó, además, una sala de lectura.

A finales de 2006 y principios de 2007 se hace el cableado de una nueva red con un ancho de banda mayor. Se dotó de nuevo equipo de cómputo al personal académico, administrativo y para el servicio, lo cual no ha permitido una mejor respuesta a las solicitudes de búsquedas. Se redistribuyeron los espacios que ocupan el personal administrativo y académico, así como las áreas de lectura y servicio de cómputo exclusivo para usuarios. Se renovó el mobiliario del departamento: exhibidores, sillones, estantes, archiveros, mesas, sillas. Por otra parte, se inició la remodelación del cubículo de la jefatura. Finalmente, fue liberada para su consulta la base de datos referencial BCRev (PUB01), montada en Aleph con información de revistas, tablas de contenido, el Archivo Vertical, la colección OCDE, y la colección INEGI, entre otras.

En el 2007 fue integrada en este Departamento la colección bibliohemerográfica de finales del Siglo XIX y principios del XX, que se localizaba en el Fondo Antiguo, para su resguardo, tratamiento y difusión. Se fortaleció también el intercambio de títulos por donación y canje con otras dependencias universitarias e instituciones nacionales e internacionales. Como muestra de ello, el Departamento de Publicaciones, adscrito a esta Dirección, nos ha encargado la administración de la donación y canje de la revista Biblioteca Universitaria que edita la DGB.

Después de varios años, se reinició el inventario de la colección. Se comenzó con la limpieza, reubicación y ordenamiento de la colección en estanterías; así como con la detección de fascículos duplicados y material ajeno a la colección. Esta actividad aún continua en desarrollo. De igual forma, la Subdirección de Informática nos apoyará con información automatizada y de reportes para realizar la conciliación de nuestros 
acervos con los que se encuentran en nuestro kárdex manual y en la base de datos de nuestro catálogo colectivo SERIUNAM.

\subsubsection{Necesidades}

Espacio físico para la colección: Como consideración en el corto plazo, se requiere la ampliación del espacio para las colecciones de revistas y diarios. Es urgente llevar a cabo el recorrido de las colecciones, descartar el material duplicado y efectuar donaciones de títulos que no tienen el perfil deseado de la colección. Se recomienda realizar y establecer las políticas de desarrollo de colecciones para publicaciones periódicas, políticas de descarte y las políticas de donaciones específicas para publicaciones periódicas.

Personal suficiente y calificado: El personal administrativo de servicio requiere capacitación en el manejo de fuentes de información para la mejor atención a usuarios. Es necesario ampliar la plantilla de personal académico, y proporcionarle cursos de actualización en los temas afines a publicaciones periódicas, así como definir los nuevos objetivos y actividades a la luz de estos cambios.

Establecimiento de nuevos proyectos híbridos, de digitalización y de repositorios institucionales: Es necesario trabajar en forma conjunta con otros departamentos, secciones y dependencias de la UNAM en la creación de nuevos productos y servicios que ayuden a mejorar nuestros servicios; así como compartir experiencias e información con Hela, Bibliografía Latinoamericana, Clase, Periódica, Scielo, Latindex, Catálogo Colectivo, Depto. Suscripciones, BiDi, Dgsca y eJournal, entre otras fuentes.

\subsection{Fondo Antiguo y Colecciones Especiales}

El Fondo Antiguo y Colecciones Especiales (FAyCE) es un área que nace como proyecto en la presente administración, en noviembre del año 2000, para el rescate, organización y difusión de los materiales antiguos que han permanecido bajo resguardo de la Biblioteca Central durante más de 45 años. Colegas académicos y administrativos del departamento de Selección y Adquisición Bibliográfica, en aquel entonces localizada en el piso 9, habían iniciado un inventario en Microsoft Excel, que contenía alrededor de 24,000 registros de libros y publicaciones periódicas nacionales y extranjeras. Por otra parte, en el piso 10, donde se encontraban estos libros, había otros materiales de años recientes -de las cinco primeras décadas del siglo $X X-$, lo que hacía suponer la existencia de más de 50,000 volúmenes en el fondo, según las auditorias realizadas hacia finales de la década de los noventa.

En una primera etapa, iniciada en septiembre del 2000 , se procedió a cotejar el material que se había previamente inventariado. La segunda etapa, realizada en enero del 2001, consistió en expurgar los materiales existentes cuyo perfil no justificaba su inclusión en el FAyCE con base en una serie de criterios generales -que respondieran a la relevancia y pertinencia señalados en la literatura especializada- para el libro antiguo, raro o especial, así como con las políticas internas marcadas por la Biblioteca Central.

Simultáneamente a este proceso de depuración, en el primer trimestre del año 2001, se presentó el proyecto Fondo Antiguo de la Biblioteca Central, cuyas líneas generales quedaban descritas así (Chong-de la Cruz et al, 2001, p. 26):

[...] se pretende conocer los antecedentes, inventario, salvaguarda, sistematización, conservación $y$, en su momento, la digitalización de estos materiales. Se explica la metodología a seguir para la descripción bibliográfica y ordenamiento de los materiales existentes; la creación de las bases de datos y la identificación de los materiales antiguos que se encuentran en las bibliotecas del sistema universitario, para ser integrados en el Catálogo Colectivo del Patrimonio Bibliográfico de México, que está construyendo la Biblioteca Nacional. Se mencionan también, las acciones de conservación preventiva y restauración del Fondo, además de la propuesta de remodelación del área donde se encuentran estos acervos. De igual forma, se describe brevemente la Colección en reserva y se ofrecen datos de ésta relacionados con sus años de publicación.

A continuación se mencionan brevemente algunos de los logros y experiencias más significativas obtenidas durante el periodo:

Inventario: La primera parte del inventario del 2002 arrojó 24,616 registros con monografías y publicaciones seriadas. Al término de éste, en el 2007, de acuerdo con las bases de datos y las hojas de cálculo Excel, se llegó a 50,091 registros, que incluían las colecciones reservada y contemporánea. Esta última contiene a su vez manuscritos, partituras, impresos sueltos, folletería y el legado Ezequiel $\mathrm{A}$. Chávez.

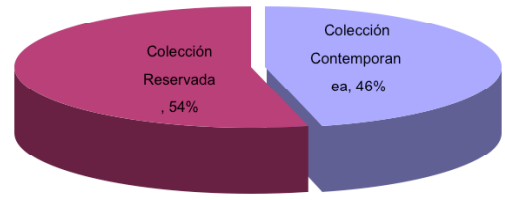

Grafico 5. Distribución del acervo del Fondo Antiguo 
Programa de estabilización y encuadernación. El rescate del fondo obligó a tomar medidas de preservación, tales como limpieza profunda en seco y elaboración de guardas y bandas de primer nivel. De 2002 a 2007 se han limpiado 6,031 libros, y se han elaborado 65 guardas de primer nivel y 20 bandas. Los fondos antiguos por su naturaleza requieren para preservarse, en ocasiones, de una intervención especializada o de una encuadernación de calidad, lo que se traduce en costos muy altos. Durante este periodo se encuadernaron 1,113 volúmenes.

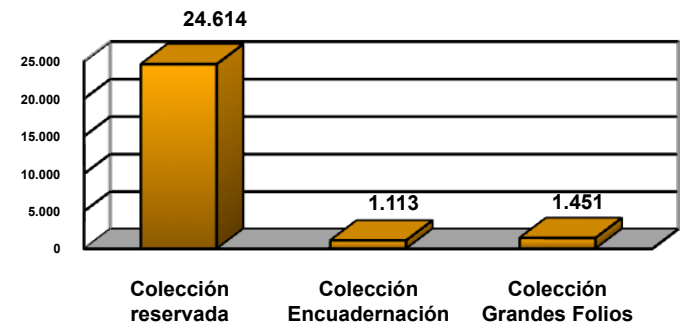

Gráfico 6. Situación del fondo.

Programa de Servicio Social y Promotores Voluntarios. Para el trabajo en el Departamento se diseñó un programa que llevaría a cabo personal de servicio social. A dos de los participantes se les contrató como personal de honorarios y, otros más, se incorporaron como promotores voluntarios.

\begin{tabular}{lc}
\hline Actividades & Resultado \\
\hline Diplomado realizados & 4 \\
Módulos programados en los cuatro diplomados & 52 \\
Sesiones programadas en los cuatro diplomados & 181 \\
Horas por los cuatro diplomados & 740 \\
Alumnos inscritos en los cuatro diplomados & 92 \\
Alumnos aprobados, hasta el 3er diplomado (1) & 71 \\
Visitas realizadas o programadas a fondos & 12 \\
antiguos & \\
Conferencias magistrales por los cuatro & 9 \\
diplomados & 76 \\
Profesores por los cuatro diplomados & 41 \\
Trabajos presentados hasta el 3er. diplomado & 31 \\
$\begin{array}{l}\text { Profesores que brindaron asesoría en los } \\
\text { trabajos finales }\end{array}$ & \\
Trabajos arbitrados y seleccionados para & 19 \\
publicación & \\
Eficiencia terminal hasta el 3er diplomado & $91.2 \%$
\end{tabular}

Tabla IV. Actividades realizadas en el Fondo Antiguo (2000-2007)

Catalogación. En el 2007, se inició la catalogación descriptiva de segundo nivel. Para ello se han normalizado los registros de acuerdo a las Reglas Angloamericanas, $2^{\text {a }}$. ed. rev; la Descripción Bibliográfica Internacional Normalizada para Publicaciones Monográficas Antiguas (ISBDA, por sus siglas en inglés), y el Formato MARC21. Los registros se están subiendo en el sistema ALEPH 500 versión 16 para su posterior visibilidad por medio de la página web de la Biblioteca Central. Esta descripción se inició con los libros antiguos del siglo XVI, los cuales, al estar en latín, requieren de un alto grado de especialización en su transcripción y traducción.

Diplomado en El libro antiguo. Se creó en conjunción con la Facultad de Filosofía y Letras, para trabajar de forma multi e interdisciplinariamente los conceptos relacionados con la historia del libro. Actualmente, va en su cuarta versión, ahora con carácter internacional y con muy buenos resultados en su conjunto (tabla IV).

Presencia nacional e internacional. El trabajo con el Fondo Antiguo de la Biblioteca Central, a lo largo de estos años, ha sido objeto de diferentes presentaciones en varios foros. En el espacio académico se han realizado tres tesis de licenciatura, con trabajos de investigación vinculados con Bases de Datos, Marcas de Fuego y Metodología para la descripción de portadas del siglo XVII, investigaciones que han permitido a los alumnos obtener su título profesional y al FAyCE contar con herramientas metodológicas que coadyuvan al trabajo académico. Dos de las tesis obtuvieron además, mención honorífica.

En el ámbito nacional, los miembros institucionales de la Asociación Mexicana de Bibliotecas e Instituciones con Fondo Antiguos, A.C (AMBIFA) votaron a favor de que el Sistema Bibliotecario con Fondos Antiguos de la UNAM representado por el Fondo Antiguo y Colecciones Especiales- fungiera en la primera mesa directiva. El cargo obtenido fue el de la Secretaría. Internacionalmente, el trabajo del FAyCE ha sido presentado en la Federación Internacional de Asociaciones de Bibliotecarios y Bibliotecas (IFLA, por sus siglas en inglés) por medio de una ponencia póster en Berlín, Alemania, en el año de 2003. Asimismo, se han presentado y validado los avances catalográficos ante colegas de la Biblioteca Nacional de España y de la Universidad Complutense.

\section{Notas}

(1) El cuarto diplomado termina su primera fase el 8 de diciembre de 2007 y aún faltan 150 horas de la segunda fase que iniciará en enero de 2008.

\section{Referencias}

Chong; de la Cruz; et al. (2001). Fondo Antiguo de la Biblioteca Central. // Biblioteca Universitaria, Nueva Época. 4:1 (2001) 